\title{
Study of Mumps in Children attending a Tertiary Care Centre
}

\author{
Keyal K' ${ }^{1}$ Joshi BG², Bhatt $\mathrm{S}^{3}$, Pandey $\mathrm{R}^{4}$, Shrestha RM ${ }^{5}$ \\ ${ }^{1}$ Dr. Kabita Keyal, MBBS, MD, Registrar, ${ }^{2}$ Dr. Binita Gurubacharya Joshi, MBBS, MD, ${ }^{3}$ Dr. Shanti Bhatt, MBBS, MD, \\ ${ }^{4}$ Dr. Rajesh Pandey, MBBS, Medical Officer, ${ }^{5}$ Dr. Rameshwar Man Shrestha, MBBS, MD (Hons), Consultant Paediatrician. All \\ from the Department of Paediatric Medicine, Civil Service Hospital of Nepal.
}

Address for correspondence: Dr. Kabita Keyal, E-mail: kabitakey@yahoo.com

\begin{abstract}
Introduction: Mumps is a self-limiting viral infection of the salivary glands with systemic manifestations and complications. It primarily affects young children, with increased incidence in winter and spring. Mumps infection is endemic in developing countries because of poor vaccination coverage. This study is intended to highlight the increased number of mumps cases in children attending tertiary care center in Nepal and thus to emphasize the importance of mumps vaccination, so as to decrease the disease occurrence and disease burden by vaccinating all children. Materials and Methods: This was a prospective study done in Civil Service Hospital of Nepal over a period of 2 years from November 2009 to October 2011. All children less than 14years of age with symptoms of fever and parotid swelling were included in the study group. A detailed history pertaining to the disease was taken, that included; history of exposure and prior vaccination against mumps. Children were asked to follow up either after 5 days or in case of noticing any signs and symptoms of complication. Results: There were total 113 cases diagnosed clinically as mumps of which there were 71 males (62.83\%) and 42 females (37.16\%) with the peak incidence of disease in the month of March and September with 22 cases (19.46\%) in each month. The increase incidence was seen in 4-6 years of age with 58 cases $(51.32 \%)$. There were 70 patients $(61.94 \%)$ that had history of exposure to mumps infection. All the patients in this study had either unilateral or bilateral parotitis. None of the children were vaccinated against mumps. And all the school going children had to be off school for a period of 3-5 days. Conclusion: There were large number of children with mumps and none of them were vaccinated. Child can be prevented from the infection by vaccination and thus avoiding possible sufferings and complications. Thus we recommend the use of mumps vaccination in Routine immunization programme.
\end{abstract}

Key words: Mumps, Parotitis, School absenteeism, Nepal, Vaccine

\section{Introduction}

$\mathrm{M}$ umps is an acute self-limited infection characterized by fever, bilateral or unilateral parotid swelling and tenderness. It is caused by mumps virus which belongs to Paramyxoviridae family and the genus Rubulavirus. Mumps can occur at any age but it primarily affects the school going children between 5- 9 years of age. There is increased incidence in winter and spring season'. Mumps infection is endemic in developing countries because of poor vaccination coverage. Humans are the only known host. It is transmitted by droplet spread or by direct contact with infected cases. Mumps virus commonly targets the salivary gland, central nervous system, pancreas and testes ${ }^{2}$. Lack of immunization, travelling and immune deficiencies can make a child more prone to infection. Lifelong immunity follows after natural infection ${ }^{2}$. The incubation period is $12-25$ days with period of maximum infectivity being 2 days prior to 5 days after the parotid swelling ${ }^{3,4,5}$. Patient may present with prodromal symptoms of fever, headache malaise, vomiting followed by unilateral parotid gland swelling ${ }^{6}$. The enlargement of contra lateral gland occurs 1-5 days later in almost $70 \%$ of the cases ${ }^{2,7}$. Complications are usually infrequent but infection can progress to meningitis, encephalitis, pancreatitis, oophoritis, orchitis, epididymitis, leading to sterility or infertility and rarely sensorineural hearing loss, myocarditis, pneumonia, transient renal dysfunction, thyroiditis, optic neuritis etc ${ }^{8}$. 
Diagnosis of mumps is usually clinical on the basis of history, presence of parotid swelling (Parotitis) unilateral or bilateral and history of exposure but several non-specific findings may be present in blood like: elevated WBC count with lymphocyte predominance, increased serum amylase level. Other tests that can be done are: Solid phase ELISA, Virus isolation from the CSF during the first 2-3 days of disease onset. Now a newer diagnostic confirmation using real time nessed polymerase chain reaction has been developed ${ }^{9}$. But none of these tests are available in Nepal. In cases of complication further testing is required to determine the organ system involved.

Treatment is usually conservative and symptomatic with analgesics, antipyretics, along with bed rest, soft light diet and generous fluid intake. In case of complication it may require admission and further management. The only effective way to prevent mumps is by vaccination.

Mumps is generally a mild disease but can cause unnecessary sufferings and absenteeism from school and work and may lead to rare but serious complications. As data provided by $\mathrm{WHO}$, there were 29,022 reported cases of mumps from Nepal (data as of 20-September-2011) ${ }^{10}$. To our knowledge there hasn't been any study done in Nepal and there is no schedule for mumps vaccination till date in routine national immunization programme of Nepal. Hence this study is intended to highlight the increased number of mumps cases in children attending tertiary care center in Nepal and thus to emphasize the importance of mumps vaccination, so as to decrease the disease occurrence and disease burden by vaccinating all children.

\section{Materials and Methods}

This was a prospective study done in Civil Service Hospital of Nepal over a period of 2 years from November 2009 to October 2011. All children less than 14years of age with symptoms of fever and parotid swelling were included in the study group. A detailed history pertaining to the disease was taken, that included; history of exposure and prior vaccination against mumps. Children were asked to follow up either after 5 days or in case of noticing any signs and symptoms of complication. There is no virological test available in Nepal to diagnose mumps hence the diagnosis of mumps in our study was completely on clinical grounds.

\section{Results}

In this study there were a total of 113 clinically diagnosed cases of mumps out of which there were 71 males and 42 females with male:female ratio being 1.69:1.

Only $7(6.19 \%)$ out of 113 children with mumps were admitted in our hospital for management of mumps complication, out of which four children were managed for mumps cellulitis and three for mumps pancreatitis.

None of the children were vaccinated against mumps. Most of the school going children had to be absent from school for the period of 3-5 days.

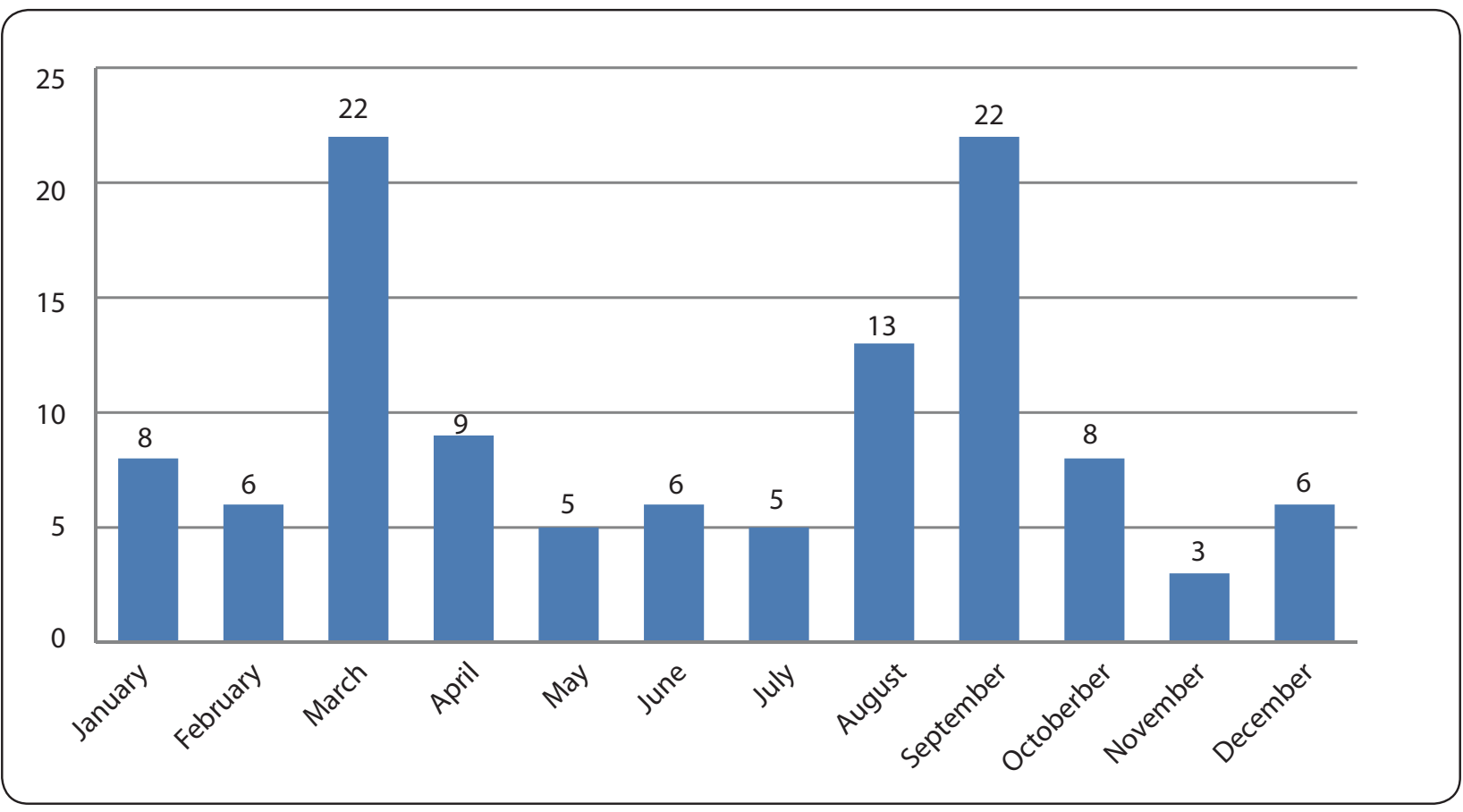

Fig 1: Graph showing the monthly occurance of mumps 


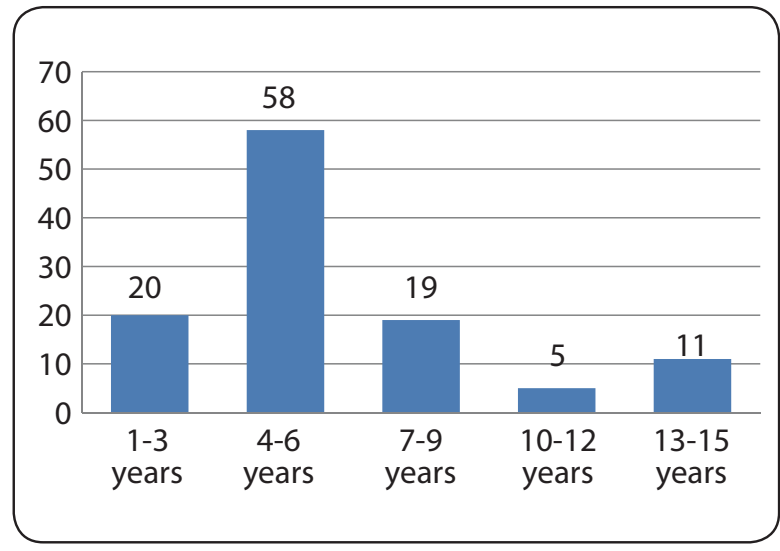

Fig 2: Graph showing age distribution of mumps cases.

\section{Discussion}

Mumps is one of the common contagious viral diseases seen in children attending pediatric clinics. According to the $\mathrm{WHO}$, there were 29,022 cases of mumps reported from Nepal (data as of 20-September-2011) ${ }^{10}$. In our hospital based study done over a period of 2 years, there were 113 cases of mumps in children less than 14 years of age. The commonest age group affected was 4-6 years (51.32\%).Out of 113 children, males had higher incidence of disease (male: female ratio of 1.69:1). Peak incidence of the disease occurred in the month of March and September (19.46\% each), as compared to study done by D Whyte in mid -west of Ireland from 20042008 notified 319 cases of mumps with peak incidence in autumn and slight preponderance of cases in males over females ${ }^{8}$.

During 2006, a total of 6584 confirmed and probable cases of mumps were reported in United States to the Centers for Disease Control and Prevention and most of these, 5865, occurred between January 1 and July 31 with the peak of the outbreak was in April ' ${ }^{1}$. There was increased incidence of mumps in 5-14years of age as shown in study done by Galbraith in Wales in 1986 with peak from June August and a later peak in December ${ }^{11}$.

In the study done by T. Jacob John during an outbreak of mumps in Thiruvananthapuram district in 2002, they found that over a period of 3 months the peak prevalence was seen in 5-9 years age, with 98 reported cases out of total 179 , and there as a male preponderance The study also revealed an outbreak with a peak during Jan-March ${ }^{12}$.

In the study done by Hashimoto $\mathrm{H}$, they reported that most of the mumps cases occured in school aged children of 5 -14yrs age (60\%) during 1985-1987 ${ }^{13}$. Another study done by SR Palmer also confirms that most of them occurred in preschool children ${ }^{14}$.

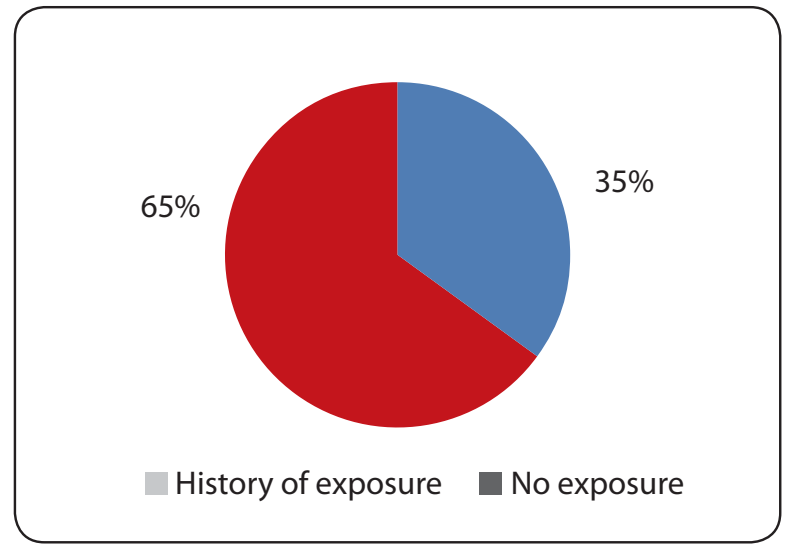

Fig 3: Pie chart showing history of exposure to infected cases of mumps

Painful swelling of the salivary glands (classically the parotid gland) is the most typical presentation ${ }^{15}$. Our study showed that $49(43.36 \%)$ had bilateral and $64(56.63 \%)$ had unilateral parotid swelling. All the children had to be off school or work for a period of 3-5 days.

We also found that none of the children were vaccinated against mumps. After the licensure of the mumps vaccine in the United States in December 1967, there were 666 cases of mumps reported in 1998, which reflect a $99 \%$ decrease in contrast to 152,209 cases reported in 1968. Since 2001 there was average of only 265 cases per year ${ }^{16}$. In 2003, the Centers for disease control and prevention (CDC) reported a total of 231 cases in United States ${ }^{17}$. Studies done on mumps vaccine in the United States and elsewhere have demonstrated that a single dose of mumps or MMR vaccine is approximately 80\% (range 61-91\%) effective and two doses being approximately $90 \%$ effective in preventing mumps disease ${ }^{7,18}$. During the current outbreak of mumps in the United Kingdom, two doses of a mumps vaccine have been $95 \%$ effective in preventing disease ${ }^{19}$. A two-dose MMR vaccination program eliminated mumps from Finland ${ }^{20}$. While in developing countries like Nepal most of the population is still unaware of mumps vaccine and this is not a part of routine immunization programme in Nepal.

\section{Conclusion}

Mumps was one of the common viral illnesses in children attending pediatric OPD of our hospital. All of them presented with fever and parotitis and none of them were vaccinated. All of the children had to be off school and work for a period of 3-5 days. Though the disease is self limiting, child can be prevented from the infection by vaccination and thus avoiding possible sufferings and complications. Thus we recommend the use of mumps vaccination as a part of the routine immunization programme in Nepal. 
Acknowledgements: None

Funding: None

Conflict of Interest: None

Permission from IRB: Yes

\section{References}

1. Anderson LJ, Seward JF. Mumps Epidemiology and Immunity: The Anatomy of a Modern Epidemic. Pediatr Infect Dis J 2008:27(10):S75-S79 doi: 10.1097/ INF.0b013e3181684d8d

2. Mason WH. Mumps. In: Kliegman RM, Behrman RE, Jenson HB, Stanton BF. Nelson Textbook of Pediatrics. 18th ed. Philadelphia, Pa: Saunders Elsevier; 2007.p.1341-344.

3. Henle G, Henle W, Wendell KK, Rosenber P. Isolation of mumps virus from human beings with induced apparent or inapparent infections. J Exp Med 1948;88:223-32.

4. Chiba Y, Horino K, Umetsu M, Wataya Y, Chiba S. Virus excretion and antibody response in saliva in natural mumps. Tohoku J Exp Med 1973;111:229-38.

5. Polgreen PM, Bohnett LC, Cavanaugh JE, Gingerich $\mathrm{SB}$, Desjardin LE, Harris ML, et al. The duration of mumps virus shedding after the onset of symptoms. Clin Infect Dis 2008;46(9):1447-9.

6. Falk WA, Buchan K, Dow M, et al. The epidemiology of mumps in southern Alberta 1980-1982. Am J Epidemiol 1989;130:736-749.

7. Plotkin SA. Mumps vaccine. In: Plotkin SA, Orenstein WA, eds. Vaccines. 4th ed. Philadelphia, PA: Saunders; 2004:p.441-469.

8. Whyte D, O'Dea F, McDonnell C, O'Connell NH, Callinan S, Brosnan $E$, et. al. Mumps epidemiology in the Mid-West of Ireland 2004-2008: increasing disease burden in the university/college setting. Euro Surveill 2009;14(16):19182.

9. Krause $\mathrm{CH}$, Eastick $\mathrm{K}$, Ogilvie MM. "Real-time PCR for mumps diagnosis on clinical specimens-- comparison with results of conventional methods of virus detection and nested PCR". J Clin Virol 2006;37(3):184-9. doi:10.1016/j.jcv.2006.07.009.

10. WHO vaccine-preventable diseases: monitoring system 2011 global summary. Available from:http:// apps.who.int/immunization_monitoring/en/ globalsummary/timeseries/tsincidencemum.htm

11. Galbraith NS,Pusey JJ,Young SEJ, et al. Mumps surveillance in England and Wales 1962-81. Lancet 1984;1:91-4.

12. John TJ, Samuel R, Balraj V, John R. Disease surveillance at district level: a model for developing countries. Lancet 1998;352:58-61.

13. Hashimoto $H$, Fujioka $M$, Kinumaki H. An officebased prospective study of deafness in mumps. Pediatr Infect Dis J 2009;28(3):173-5.

14. Palmer S.R, Biffin A, Horner G, Griffiths J.D. Incidence of mumps in Wales in 1986. J Royal Coll Gen Prac 1989;39(318): 34

15. Hviid A, Rubin S, Mühlemann K. Mumps. Lancet 2008;371:932-44.

16. Cem S Demirci, Russell W Steele. Mumps. Pediatr Infect Dis J 2009;28(3):173-5.

17. CDC. Revised U.S. surveillance case definition for severe acute respiratory syndrome (SARS) and update on SARS cases--United States and worldwide. Morb Mortal Wkly Rep 2003;52(49):1202-6.

18. Peltola H, Kulkarni PS, Kapre SV, Paunio M, Jadhav SS, Dhere RM. Mumps outbreaks in Canada and the United States: time for new thinking on mumps vaccines. Clin Infect Dis 2007;45:459-66.

19. Cohen C, White JM, Savage EJ, et al. Vaccine effectiveness estimates, 2004-2005 mumps outbreak, England. Emerg Infect Dis 2007;13:12-17.

20. Peltola H, Davidkin I, Paunio M, Valle M, Leinikki P, Heinonen OP. Mumps and rubella eliminated from Finland. JAMA 2000;284:2643-47.

\section{How to cite this article?}

Keyal K, Joshi BG, Bhatt S, Pandey R, Shrestha RM. Study of Mumps in Children attending a Tertiary Care Centre. J Nepal Paediatr Soc 2012;32(1):53-56. 